\title{
GENETIC DIFFERENTIATION OF UKRAINIAN POPULATIONS OF EUSOMUS OVULUM (COLEOPTERA, CURCULIONIDAE): EVIDENCE OF MULTIPLE HYBRID SPECIATION
}

\author{
S. Yu. Morozov-Leonov ${ }^{1^{*}}$, V. Yu. Nazarenko ${ }^{2}$ \\ Schmalhausen Institute of Zoology NAS of Ukraine \\ vul. B. Khmelnytskogo, 15, Kyiv, 01030, Ukraine \\ ${ }^{1}$ E-mail: morleone2000@yahoo.com \\ ${ }^{2}$ E-mail: nazarenko@izan.kiev.ua \\ * Corresponding author \\ S. Yu. Morozov-Leonov (https://orcid.org/0000-0003-1784-7753) \\ V. Yu. Nazarenko (https://orcid.org/0000-0003-4245-5049)
}

Genetic Differentiation of Ukrainian Populations of Eusomus ovulum (Coleoptera, Curculionidae): Evidence of Multiple Hybrid Speciation. Morozov-Leonov, S. Yu., Nazarenko, V. Yu. - The clonal structure of populations of the weevil Eusomus ovulum Germar, 1824 (Coleoptera, Curculionidae) from several regions of Ukraine was analyzed. The significant differentiation between populations from different region was demonstrated. The hypothesis of multiple origins of the hybrid form E. ovulum from several parental species is proposed.

Key words: weevil, Curculionidae, Eusomus, allozyme, polyclonal structure, multiple hybrid speciation.

\section{Introduction}

Natural hybridization is widely distributed in nature (Arnold, 2003; Avise, 2008). The consequences of hybridization are various. Hybrids are often sterile (Feng et al., 2020). Numerous fertile hybrids can be an important component of the populations of parental species (Konopiński, Amirowicz, 2018.). Finally, hybridization generates sometimes a new genetic form that differs from both parental species and is capable to reproduce autonomically (hybrid speciation) (Mallet, 2007; Vallejo-Marín, Hiscock, 2016). In particular, many hybrid forms with a species status are known among weevils (Coleoptera, Curculionidae) (Kajtoch, LachowskaCierlik, 2009; Stenberg, Lokki, Saura, 2000).

The hybrid forms of weevils are known to reproduce by parthenogenesis. There is the opinion that parthenogenesis is a very effective mode to provide fertility within such hybrid forms (Dedukh et al., 2020). One of the consequences of parthenogenetic reproduction is the clonal structure of the offspring. Parthenogenetic hybrid forms of weevils with a species status can be monoclonal or polyclonal (Nazarenko, Morozov-Leonov, 2018). The monoclonality of the hybrid form has a simple explanation. A single clone may come from a single 
hybrid female. The origin of polyclonality is not so simple. First, the emergence of new clones can be a result of mutations (Vorburger, 2008). However, the study of the genetic variability of many clonal forms shows that their polyclonality is the result of multiple hybridization of the parental species (Collares-Pereira and Coelho, 2010; Mezhzherin et al., 2019; Bogart, 2019). It is obvious that the hybrid form, which occurred as a result of repeated acts of hybridization of the parental species, has a high level of genetic variability and a significant evolutionary potential. Therefore, for a correct assessment of the evolutionary prospects of any polyclonal genetic form, it is necessary to reconstruct its origin.

Among the model species suitable for evolutionary genetic studies, weevils of the family Curculionidae are very promising (Stenberg et al., 2003; Stenberg, Lundmark, 2004). First, this family contains both Mendelian species and parthenogenetic ones. Second, these parthenogenetic forms are known to be polyploid hybrids. Thus, the study of the genetic structure of populations of parthenogenetic forms of weevils will make it possible to assess the evolutionary prospects of both hybrid forms and clonal reproduction.

Previous studies have revealed the complex polyclonal structure of many parthenogenetic forms of weevils. Thus, the studies of the well-known weevil O. scaber showed the existence of noticeable genetic differentiation between geographically distant populations (Stenberg et al., 1997, 2000). More recent studies have demonstrated the interpopulation differentiation of other parthenogenetic forms of weevils, such as Polydrusus inustus (Kajtoch, Lachowska-Cierlik, Mazur, 2009; Kajtoch, Korotyaev, Lachowska-Cierlik, 2011), Eusomus ovulum (Mazur et al., 2016), and Strophosoma melanogrammum (Kotásková, Kolasa, Kajtoch, 2018). The value of interpopulation differentiation could be small (in case of E. ovulum) or relatively high (between $P$. inustus populations). Earlier, we detected genetic differentiation of geographically distant Otiorhynchus ligustici populations (Morozov-Leonov, Nazarenko, 2016). However, the populations we studied were within the same geographic region and differed in a single gene. This difference may be the result of mutation and successful reproduction of a mutant clone. Therefore, the aim of our study was to analyze the genetic variability of populations of the polyclonal parthenogenetic weevil species that are located within several geographically distant regions.

\section{Material and methods}

For a detailed analysis, we used a widespread polyclonal species Eusomus ovulum Germar, 1824 (Coleoptera, Curculionidae, Sciaphilini) (Nazarenko, Morozov-Leonov, 2018; Mazur et al., 2016).

The material for this work was collected in 2017-2019. The distance between the most distant samples is approx. $700 \mathrm{~km}$, from north to south $400 \mathrm{~km}$. Samples were taken from 13 populations located on the territory of western, central, southern and eastern Ukraine (table 1, fig. 1) (decimal latitude and longitude of each data collection point are indicated in parentheses).

No. 1 - vicinity of Lutsk $(50.734,25.324), 24$ specimens; No. 2 - near Buscha, 13 specimens (50.303,26.237); No. 3 - near Buderash, 20 specimens (50.303, 26.237); No. 4 - near Novomalyn, 18 specimens (50.300, 26.351); No. 5 - Lisnyky, 11 specimens (50.294, 30.529); No. 6 - Pidhirtsi, 61 specimens (50.245, 30.550); No. 7 - Baryshivka, 11 specimens (50.363, 31.279); No. 8 - near Rankovyy, 61 specimens (50.236, 31.724); No. 9 - Tashyne, 20 specimens (46.902, 31.120); No. 10 - Tyagynka, 46 specimens (46.784, 33.036); No. 11 - Askaniya Nova, 27 specimens (46.454, 33.870); No. 12 - Gaydary, 24 specimens (49.626, 36.331); No. 13 - Siversky Donets floodplain, 10 specimens $(49.631,36.299)$.

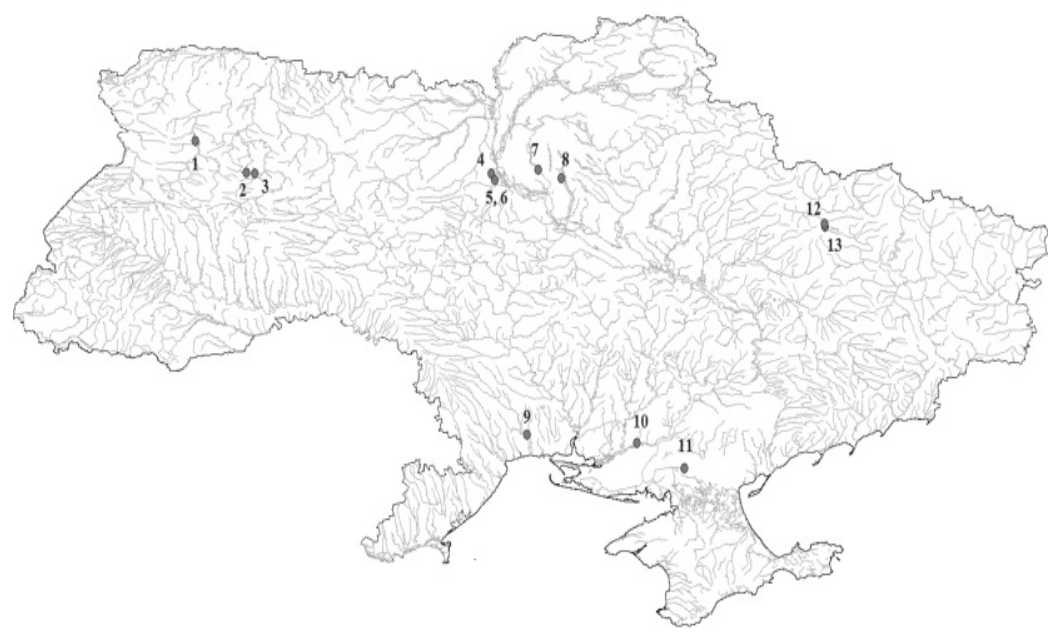

Fig. 1. Geographic localization of Eusomus ovulum samples. 
We have studied the electrophoretic variability of esterases (Es-1, 2, 3, 4, 5) that are known to be highly polymorphic within weevil species (Morozov-Leonov, Nazarenko, 2016; Nazarenko, Morozov-Leonov, 2018). The thoracic segments of every weevil were frozen during 12 hours, then used in the acrylamide electrophoresis. Sample preparation, electrophoretic analysis of esterases, the data interpretation were performed by standard methods (Harris, Hopkinson, 1976). All heterozygous phenotypes are indicated without clarification of the gene dosage. Such designation is used because phenotypes like 100/100/113 and 100/113/113 sometimes cannot be reliably distinguished (fig. 2). Therefore, we designated all heterozygous phenotypes like as 100/113.

\section{Results}

Allelic variability of the studied genes. Of the five studied genes encoding nonspecific esterases, 4 are represented by several alleles (table 1, fig. 2).

The gene encoding Es-1 is represented by two alleles in the studied samples - Es- $1^{0}$ and Es- $1^{91}$ (fig. 1). All identified genotypes were homozygous Es- $1^{0 / 0}$ (clone Eo4) and Es- $1^{91 / 91}$ (all other clones). The Es- $1^{0}$ allele was detected in samples 9-12 only (southern and eastern Ukraine).

The gene encoding Es-2 does not show variability detected electrophoretically. In all samples, it is represented by a single allele Es- $2^{82}$.

The Es-3 gene is represented by two alleles (Es- $3^{113}$ and Es- $3^{118}$ ). The homozygous genotype Es- $3^{118 / 118}$ is characteristic for Eo5 clone. All other clones have a heterozygous genotype Es- $3^{113 / 118}$.

The Es- 4 gene is represented by three alleles $\left(\right.$ Es- $4^{89}$, Es- $4^{100}$, Es- $\left.4^{113}\right)$. The Es- $4^{89}$ allele was found in the Es- $4^{89 / 100}$ genotype only that is characteristic for Eo5 clone. The homozygous genotype Es- $4^{100 / 100}$ is characteristic for Eo2 clone. All other clones (Eo1, Eo3, Eo4) have a heterozygous genotype Es- $4^{100 / 113}$.

The Es- 5 gene is represented by three alleles Es $-5^{0}$, Es- $5^{81}$ and Es- $5^{100}$. Allele Es- $5^{81}$ in the heterozygous genotype Es- $5^{81 / 100}$ is characteristic only for clone Eo5. Allele Es- $5^{0}$ is found in

Table 1. The electrophoretic phenotypes of clones in Eusomus ovulum samples from Ukrainian populations

\begin{tabular}{|c|c|c|c|c|c|c|c|c|c|c|c|c|c|c|c|c|c|c|c|}
\hline \multicolumn{6}{|c|}{ Clone } & \multirow{2}{*}{\multicolumn{13}{|c|}{ Sample }} & \multirow{3}{*}{ 丞 } \\
\hline \multirow{2}{*}{ No. } & \multicolumn{5}{|c|}{ Gene } & & & & & & & & & & & & & & \\
\hline & Es-1 & $E s-2$ & Es-3 & $E s-4$ & Es-5 & 1 & 2 & 3 & 4 & 5 & 6 & 7 & 8 & 9 & \begin{tabular}{|l|l|}
10 \\
\end{tabular} & \begin{tabular}{|l|}
11 \\
\end{tabular} & \begin{tabular}{|l|}
12 \\
\end{tabular} & \begin{tabular}{|l|}
13 \\
\end{tabular} & \\
\hline Eo1 & 91 & 82 & $113 / 118$ & $100 / 113$ & 100 & 23 & 13 & 20 & 18 & 11 & 58 & 11 & 61 & 18 & 22 & & 2 & & 257 \\
\hline Eo2 & 91 & 82 & $113 / 118$ & 100 & 100 & & & & & & 3 & & & & & & & & 3 \\
\hline Eo3 & 91 & 82 & $113 / 118$ & $100 / 113$ & 0 & 1 & & & & & & & & & & & 19 & & 20 \\
\hline Eo4 & 0 & 82 & $113 / 118$ & $100 / 113$ & 0 & & & & & & & & & 2 & 24 & 27 & 3 & & 56 \\
\hline $\begin{array}{l}\text { Eo5 } \\
\text { n }\end{array}$ & 91 & 82 & 118 & $89 / 100$ & $81 / 100$ & 24 & 13 & 20 & 18 & 11 & 61 & 11 & 61 & 20 & 46 & 27 & 24 & $\begin{array}{l}10 \\
10\end{array}$ & $\begin{array}{c}10 \\
346\end{array}$ \\
\hline
\end{tabular}

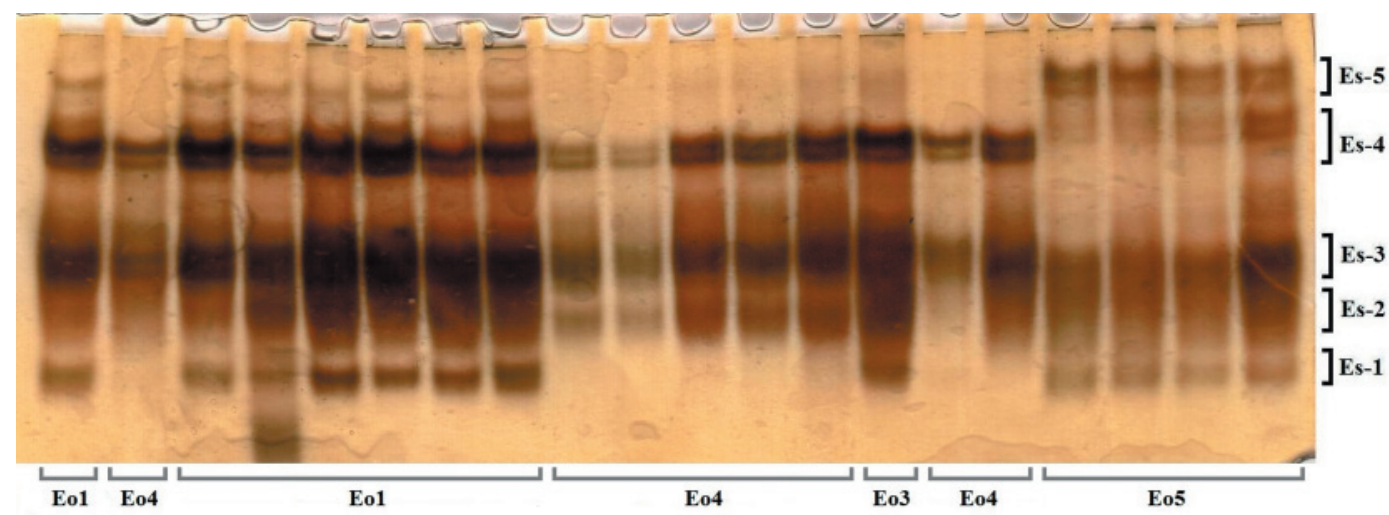

Fig. 2. The electrophoretic spectra of the esterases in the Eusomus ovulum specimens. 


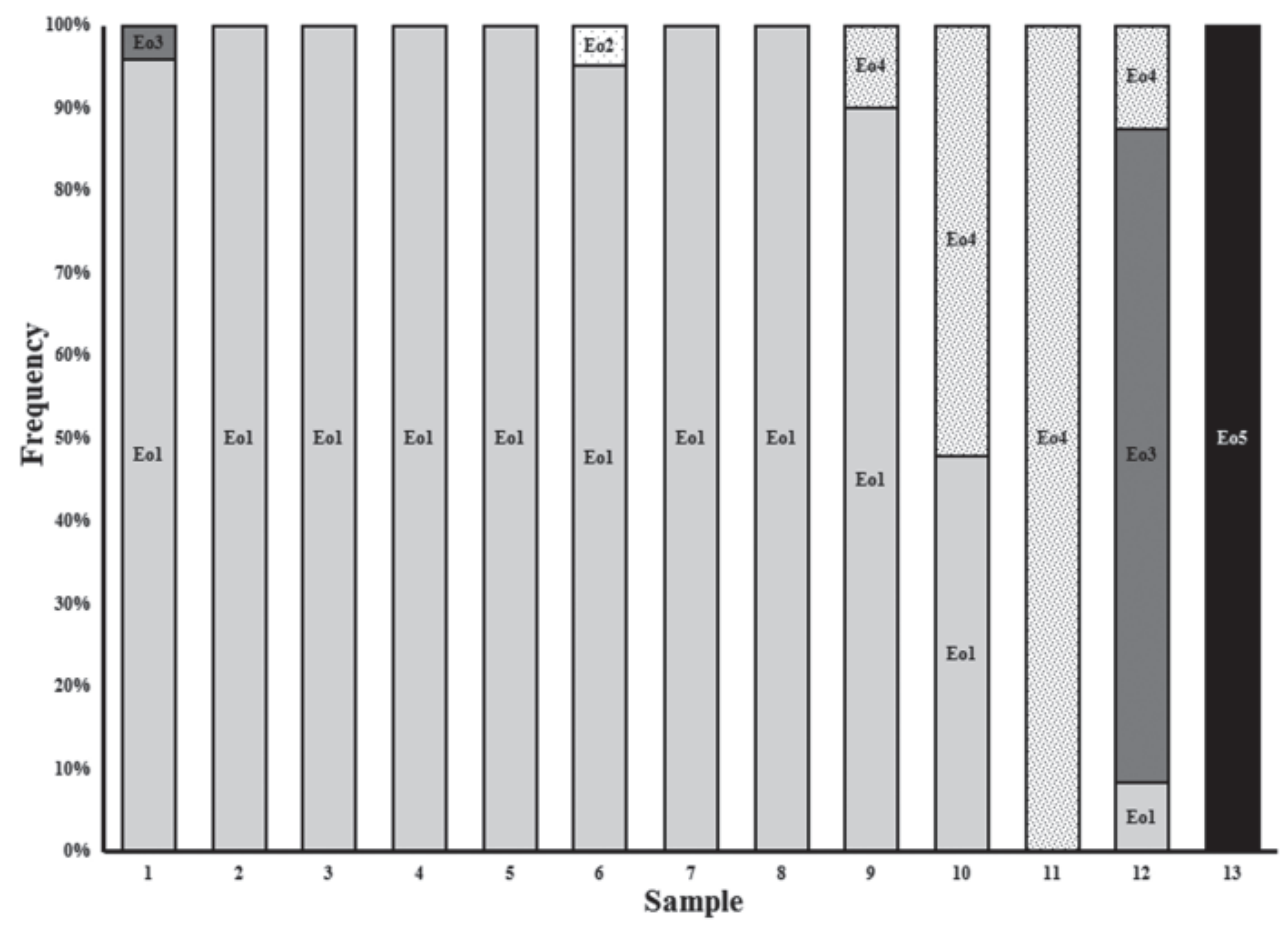

Fig. 3. Polyclonal structure of studied Eusomus ovlulum samples inUkraine.

the homozygous genotype Es- $5^{0 / 0}$ and is characteristic for clones Eo3, Eo4. The allele Es-5 $5^{100}$ (genotype Es- $5^{100 / 100}$ ) is typical for clones Eo1, Eo2.

Polyclonal structure of Eusomus ovulum populations in Ukraine. In the Ukrainian populations of Eusomus ovulum, 5 clones were identified (table 1, fig. 3). Moreover, the Eo2 clone was rare - its frequency is 0.009 . The frequencies of other clones vary from 0.029 (Eo5) to 0.743 (Eo1).

The number of clones within a single sample varies from 3 (sample 12) or 2 (samples $1,6,9,10)$ to 1 (all other samples).

Two of the identified clones were found in one sample only. These are clones Eo2 (sample 6) and Eo5 (sample 13). Clone Eo4 was identified in samples 9-12. The most numerous clone Eo1 was found in almost all samples, except for samples 11 and 13.

Genetic differentiation of Eusomus ovulum clones in Ukrainian populations. Analysis of the studied genes variation allows to divide the identified clones into three groups. The first group includes clone Eo1 and clones Eo2 and Eo3 that are genetically close (table 1). They have a similar set of alleles and differ from clone Eo1 in one gene (Es-4 for clone Eo2 and Es-5 for clone Eo3).

Clone Eo4 should be referred to the second group. It also has a set of alleles that is similar to Eo1 clone, but differs from it in the genotypic composition of two genes (Es-1 and Es-5).

Finally, the third group consists of a single clone Eo5. Its allelic set differs from all others in the presence of alleles detected only in this clone (Es- $4^{89}$ and Es- $5^{81}$ ).

Features of the geographical distribution of the identified clones. None of the identified clones were found in all studied samples. The most numerous clone Eo 1 was found in all regions, except for the most eastern one (the Siversky Donets floodplain). A local clone Eo2 was identified in one of the samples from central Ukraine. Clone Eo3 is located on the right shore of the Siversky Donets River. The discovery of a single specimen 
carrying this clone on the territory of western Ukraine requires a more detailed analysis of populations from there. Clone Eo4 is widespread in samples from southern and eastern Ukraine, except for sample 13, which is located farther than all others in the eastern direction. Clone Eo5 was recorded in the sample from the Siversky Donets floodplain.

\section{Discussion}

Allelic variability of the studied genes. Clonal forms of weevils are characterized by constant heterozygosity for some of the studied genes (Nazarenko, Morozov-Leonov, 2018). Our data, resulting from this study, confirm this pattern, which clearly marks the hybrid nature of parthenogenetic forms of weevils (Kajtoch, Lachowska-Cierlik, 2009).

Polyclonal structure of Eusomus ovulum populations in Ukraine. The Eusomus ovulum species as a whole can be characterized as having a polyclonal structure, in contrast to some previously studied related monoclonal forms of hybrid origin (Nazarenko, Morozov-Leonov, 2018). Our results, obtained using electrophoretic analysis of enzymes, are consistent with those of other researchers who have studied the variability of DNA sequences (Mazur et al., 2016). In both cases, variability of the studied characters and interpopulation differentiation were found.

Genetic differentiation of Ukrainian populations of the parthenogenetic clonal form Eusomus ovulum and their origin. Analysis of the allelic variation within the studied E. ovulum populations requires an explanation. First of all, it is necessary to offer a reasonable explanation for the existence of the Eo5 clone, which differs markedly from all other clones detected in the Ukrainian populations of E. ovulum. Three hypotheses can be proposed to explain the observed interpopulation differentiation of this species.

First, clone Eo5 may be of mutant origin. The successful expansion of a clone derived from a single mutant specimen is theoretically possible. In nature, the cases are known of a single clone successful dispersal in many populations within a large geographic region (Hotz et al., 2008). Moreover, there are cases when in some populations the frequency of an initially rare (hemi) clone increases significantly (Morozov-Leonov, 2017). However, in that case of E. ovulum, the hypothesis of the mutant origin of Eo5 suggests a two-step process of the appearance within one clone of two mutations in two different genes (Es-4 and Es-5). The probaility of such a coordinated mutagenesis of two different genes seems to be low. A more reliable test of this hypothesis requires the study of other E. ovulum populations located in eastern Ukraine.

Second, clones of E. ovulum could arise from hybridization of two polymorphic Mendelian species. This hypothesis provides the simplest explanation for the observed polyclonal structure of the studied weevil species. Is it known that many polymorphic hybrid forms are derived from polymorphic ancestral species (Arioli, Jakob, Reyer, 2010). However, in this case, the problem of explaining the significant interpopulation differentiation of parthenogenetic E. ovulum remains in the form of a problem of significant differentiation of its ancestral species. The weak point of this hypothesis is the lack of data on the clonal forms of E. ovulum that are genetically intermediate between both groups of clones (Eo1-4 and E05). To confirm or deny this hypothesis, a detailed genetic analysis of the populations of the Mendelian species that is ancestral for the parthenogenetic form E. ovulum, is required. Unfortunately, at the moment, no populations of the species ancestral for E. ovulum have been found, unlike O. scaber, for example, where populations of the ancestral Mendelian species are known (Stenberg et al., 2003; Stenberg, Lundmark, 2004).

Finally, third, clones of E. ovulum could have come from hybridization of more than two parental Mendelian species. It can be assumed that one Mendelian ancestor species (spe- 
Table 2.Hypothetical reconstruction of E. ovulum clones origin on the territory of Ukraine

\begin{tabular}{|c|c|c|c|c|c|c|}
\hline \multicolumn{2}{|c|}{ Species A } & \multicolumn{2}{|c|}{ Hybrid clone } & \multicolumn{3}{|c|}{ Other parental species } \\
\hline Alleles & Gametes & Number & Genotype & Gametes & Alleles & \\
\hline \multirow[t]{5}{*}{$\begin{array}{c}E s-1^{0}, E s-1^{91} \\
E s-3^{118} \\
E s-4^{100} \\
E s-5^{0}, E s-5^{100}\end{array}$} & $\begin{array}{l}E s-1^{91} \\
E s-3^{118} \\
E s-4^{100} \\
E s-5^{100}\end{array}$ & Eo5 & $\begin{array}{c}E s-1^{91 / 91} \\
E s-3^{118 / 118} \\
E s-4^{89} / 100 \\
E s-5^{81 / 100}\end{array}$ & $\begin{array}{l}E s-1^{91} \\
E s-3^{118} \\
E s-4^{89} \\
E s-5^{81}\end{array}$ & $\begin{array}{l}\text { Es- } 1^{91} \\
\text { Es- } 3^{118} \\
\text { Es-4 } \\
\text { Es-5 } \\
81\end{array}$ & 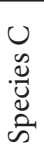 \\
\hline & & Eo1 & $\begin{array}{c}E s-1^{91 / 91} \\
E s-3^{113 / 118} \\
E s-4^{100 / 113} \\
E s-5^{100 / 100}\end{array}$ & $\begin{array}{l}E s-1^{91} \\
E s-3^{113} \\
E s-4^{113} \\
E s-5^{100}\end{array}$ & \multirow[t]{4}{*}{$\begin{array}{c}E s-1^{0}, E s-1^{91} \\
E s-3^{113} \\
E s-4^{100}, E s-4^{113} \\
E s-5^{0}, E s-5^{100}\end{array}$} & \multirow{4}{*}{ 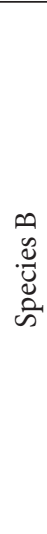 } \\
\hline & & Eo2 & $\begin{array}{c}E s-1^{91 / 91} \\
E s-3^{113 / 118} \\
E s-4^{100 / 100} \\
E s-5^{100 / 100}\end{array}$ & $\begin{array}{l}E s-1^{91} \\
E s-3^{113} \\
E s-4^{100} \\
E s-5^{100}\end{array}$ & & \\
\hline & $\begin{array}{c}E s-1^{91} \\
E s-3^{118} \\
E s-4^{100} \\
E s-5^{0}\end{array}$ & Eo3 & $\begin{array}{c}E s-1^{91 / 91} \\
E s-3^{113 / 118} \\
E s-4^{100 / 113} \\
E s-5^{0 / 0}\end{array}$ & $\begin{array}{c}E s-1^{91} \\
E s-3^{113} \\
E s-4^{113} \\
E s-5^{0}\end{array}$ & & \\
\hline & $\begin{array}{c}E s-1^{0} \\
E s-3^{118} \\
E s-4^{100} \\
E s-5^{0}\end{array}$ & Eo4 & $\begin{array}{c}E s-1^{0 / 0} \\
E s-3^{113 / 118} \\
E s-4^{100 / 113} \\
E s-5^{0 / 0}\end{array}$ & $\begin{array}{c}\text { Es- } 1^{0} \\
\text { Es-3 } 3^{113} \\
\text { Es-4 } 4^{113} \\
\text { Es-5 }\end{array}$ & & \\
\hline
\end{tabular}

cies A) was common to all existing clones (table 2). The polymorphism of this species for two genes (Es-1, Es-5) allowed it to generate more than one clone of hybrid origin. This species, as we suppose, has repeatedly hybridized with at least two other species. The second hypothetical ancestor species (species B), as shown by the obtained data, was polymorphic in three genes (Es-1, Es-4, Es-5). The hybridization "species A x species B" has occurred several times. In some populations, the alleles Es- $1^{100}$ and Es $-5^{100}$ prevailed. There, the hybridization "species A x species B" gave rise to clones Eo1, Eo2, spreading in western and central Ukraine. In other populations of this species, the Es- $5^{0}$ allele prevailed. Accordingly, the hybridization "species A x species B" gave rise to clones Eo3 and Eo4, living in the territory of eastern Ukraine. Finally, in some populations, species B had the Es- $1^{0}$, Es- $5^{0}$ alleles only. As a result, the hybrid form in this region is monoclonal and is represented by the clone Eo4 (southern Ukraine).

The third Mendelian species, hypothetically involved in hybridization (species C), was genetically distant from the two previous species. The hybridization "species A x species $\mathrm{C}$ gave rise to the clone Eo5, found in the floodplain of the Siversky Donets only and being genetically distant from the parapatric clones Eo3 and Eo4.

In fact, the third hypothesis is the development of the second one, provided that the differentiation between the populations of one of the ancestral species has reached the species level. An objection to the hypothesis of E. ovulum origin from more than 2 ancestral species may be the fact that there is no reliable morphological differentiation between different clones of this form. It should be noted that there are many known examples of extreme morphological similarities between genetically separate species. For example, such pairs of species are detected among snails (Rama Rao et al., 2018), fish (Winston, 1995; Ivankov, Kaplunenko, Borisovets, 2016) and even mammals (Stoffberg, Jacobs, Miller-Butterworth, 2004). However, a detailed analysis of the morphological variation across E. ovulum species area seems to be very promising, looking at its genetic differentiation.

Ecological preferences of Eusomus ovulum different clones. Our data show that the hybrid form Eusomus ovulum does not have a strictly limited ecological niche. Clones Eo1, Eo2 were found within the forest and forest-steppe zones. Clones Eo3, Eo4 are localized within the steppe zone. Finally, the Eo5 clone was found only in the wetland. A 
clear correlation between the clone genotype and the habitat is an additional argument in support for the hypothesis of the parthenogenetic polyclonal form Eusomus ovulum multiple hybrid origin. This line of research seems to be very promising. The existence of two genetically distant but geographically close parapatric clones deserves detailed analysis within a larger region.

\section{References}

Arioli, M., Jakob, C., Reyer, H. U. 2010. Genetic diversity in water frog hybrids (Pelophylax esculentus) varies with population structure and geographic location. Molecular Ecology, 19 (9), 1814-1828. doi: 10.1111/j.1365-294X.2010.04603.x

Arnold,M. L. 2003. Natural hybridization as an evolutionary process. Annual Review of Ecology and Systematiics, 23, 237-261. doi:10.1146/annurev.es.23.110192.001321

Avise, J. C. 2008. Clonality. The Genetics, Ecology, and Evolution of Sexual Abstinence in Vertebrate Animals. Oxford University Press, New York, 1-250.

Bogart, J. 2019. Unisexual salamanders in the genus Ambystoma. Herpetologica, 75 (4), 259-267. DOI: 10.1655/ Herpetologica-D-19-00043.1

Collares-Pereira, M. J., Coelho, M. M. 2010. Reconfirming the hybrid origin and generic status of the Iberian cyprinid complex Squalius alburnoides. Journal of Fish Biology, 76 (3), 707-15. DOI: 10.1111/j.10958649.2009.02460.x

Dedukh, D., Majtánová, Z., Marta, A., Pšenička, M., Kotusz, J., Klíma, J., Juchno, D., Alicja Boron, A., Janko, K. 2020. Parthenogenesis as a solution to hybrid sterility: the mechanistic basis of meiotic distortions in clonal and sterile hybrids. Genetics, 215 (4), 975-987. https://doi.org/10.1534/genetics.119.302988

Feng, C., Yi, H., Yang, L., Kang, M. 2020. The genetic basis of hybrid male sterility in sympatric Primulina species. BMC Evolutionary Biology, 20 (1),49-61.https://doi.org/10.1186/s12862-020-01617-4

Harris, H., Hopkinson, D. A. 1976. Handbook of Enzyme Electrophoresis in Human Genetics. North-Holland Publishing Company, Amsterdam.

Hotz, H., Guex, G. D., Beerli, P., Semlitsch, R. D., Pruvost, N. B. M. 2008. Hemiclone diversity in the hybridogenetic frog Rana esculenta outside the area of clone formation: the view from protein electrophoresis. Journal of Zoological Systematics and Evolutionary Research,46 (1), 56-62. doi:https://doi.org/10.1111/ j.1439-0469.2007.00430.x

Ivankov, V. N., Kaplunenko, V. A. Borisovets, E. E. 2016. Diagnostics of morphologically close species of Far Eastern Redfins, genus Tribolodon (Osteichthyes: Cyprinidae), by scale structure. Russian Journal of Marine Biology, 42 (5), 402-408. https://doi.org/10.1134/S1063074016050035

Kajtoch, Ł., Korotyaev, B., Lachowska-Cierlik, D. 2011. Genetic distinctness of parthenogenetic forms of European Polydrusus weevils of the subgenus Scythodrusus. Insect Science, 19 (2), 183-194. doi: 10.1111/j.17447917.2011.01448.x

Kajtoch, Ł., Lachowska-Cierlik, D., Mazur, M. 2009. Genetic diversity of the xerothermic weevils Polydrusus inustus and Centricnemus leucogrammus (Coleoptera: Curculionidae) in Central Europe. European Journal of Entomology, 106 (3), 325-334. doi: 10.14411/eje.2009.040

Kajtoch, Ł., Lachowska-Cierlik, D. 2009. Genetic constitution of parthenogenetic form of Polydrusus inustus (Coleoptera: Curculionidae) - hints of hybrid origin and recombinations. Folia Biologica-Krakow, 57 (3-4), 149-156. doi:10.3409/fb57_3-4.149-156.

Konopiński, M. K., Amirowicz, A. 2018. Genetic composition of a population of natural common bream Abramis brama $\times$ roach Rutilus rutilus hybrids and their morphological characteristics in comparison with parent species. Journal of Fish Biology, 92 (2), 365-385. doi: 10.1111/jfb.13506

Kotásková, N., Kolasa, M., Kajtoch, Ł. 2018. Contrasting patterns of molecular diversity and Wolbachia infection in bisexual and parthenogenetic Strophosoma weevils (Coleoptera: Curculionidae). Entomological science, 21 (4), 385-395. doi: 10.1111/ens.12317

Mallet, J. 2007. Hybrid speciation. Nature, 446 (7133), 279-283 DOI: 10.1038/nature05706

Mazur, M. A., Holecová, M., Lachowska-Cierlik, D., Lis, A., Kubisz, D., Kajtoch, Ł. 2016. Selective sweep of Wolbachia and parthenogenetic host genomes - the example of the weevil Eusomus ovulum. Insect Molecular Biology, 25(6), 701-711. https://doi.org/10.1111/imb.12255

Mezhzherin, S. V., Tsyba, A. A., Saliy, T. V., Lutcenko, D. S. 2019. Zone of genetic instability in polyploide hybrid spined loaches (Cypriniformes, Cobitidae, Cobitis) in the Middle Dnieper. Dopovidi Nacilonalnoi akademii nauk Ukrainy, 10, 97-103. https://doi.org/10.15407/dopovidi2019.10.097 [In Russian].

Morozov-Leonov, S. Yu. 2017. Hemiclone diversity in the hybrid form Pelophylax esculentus-ridibundus (Amphibia, Ranidae) from the Tisa river drainage. Cytology and Genetics, 51 (6), 69-77. doi:https:// doi.org/10.3103/S0095452717060093 [In Russian].

Morozov-Leonov, S. Yu., Nazarenko, V. Yu. 2016. Clonal diversity of Otiorhynchus ligustici and O. raucus (Coleoptera, Curculionidae) in Central Ukraine. Vestnik Zoologii, 51 (2), 553-556. DOI: 10.1515/vzoo2017-0016 
Nazarenko, V. Yu., Morozov-Leonov, S. Yu. 2018. Clonal structure of some weevil species (Coleoptera, Curculionidae) from Central Ukraine. Vestnik Zoologii, 52 (4), 553-556. DOI: 10.2478/vzoo-2018-0033

Rama Rao, S., Liew. T.-S., Yow, Y.-Y., Ratnayeke, S. 2018. Cryptic diversity: Two morphologically similar species of invasive apple snail in Peninsular Malaysia. PLoS ONE13 (5), e0196582. https://doi.org/10.1371/ journal.pone.0196582

Stenberg, P., Lokki, T. J., Saura, A. 2000. Clone diversity in the polyploid weevil Otiorhynchus Scaber. Hereditas, 132(2), 137-142. DOI: 10.1111/j.1601-5223.2000.00137.x

Stenberg, P., Lundmark, M. 2004. Distribution, mechanisms and evolutionary significance of clonality and polyploidy in weevils. Agricultural and Forest Entomology, 6 (4), 259-266. https://doi.org/10.1111/j.14619555.2004.00231.x

Stenberg, P., Lundmark, M., Knutelski, S., Saura, A. 2003. Evolution of clonality and polyploidy in a weevil system. Molecular Biology and Evolution, 20 (10), 1626-1632. doi: 10.1093/molbev/msg180

Stenberg, P., Terhivuo, J., Lokki, J., Saura, A. 1997. Clone diversity of tetraploid Otiorhynchus scaber in northern Europe. Hereditas, 126 (2), 169-172. doi: 10.1111/j.1601-5223.1997.00169.x

Stenberg, P., Terhivuo, J., Lokki, J., Saura, A. 2000. Clone diversity in the polyploid weevil Otiorhynchus scaber. Hereditas, 132 (2), 137-142. doi: 10.1111/j.1601-5223.2000.00137.x

Stoffberg, S., Jacobs, D. S., Miller-Butterworth C. M. 2004. Field identification of two morphologically similar bats, Miniopterus schreibersii natalensis and Miniopterus fraterculus (Chiroptera: Vespertilionidae). African Zoology, 39 (1), 47-53. https://doi.org/10.1080/15627020.2004.11407285

Vallejo-Marín, M., Hiscock, S. J. 2016. Hybridization and hybrid speciation under global change. New Phytologist, 211 (4), 1170-1187. doi: 10.1111/nph.14004

Vorburger, C. 2008. Non-hybrid offspring from matings between hemiclonal hybrid waterfrogs suggest occasional recombination between clonal genomes. Ecology letters, 4 (6), 628-636. doi: https://doi.org/10.1046/ j.1461-0248.2001.00272.x

Winston, M. R. 1995. Co-occurrence of morphologically similar species of stream fishes. The American Naturalist, 145 (4), 527-545.

Received 21 November 2020

Accepted 5 January 2021 